index comunicación | no 9 (2) 2019 | Páginas 135-162

E-ISSN: 2174-1859 | ISSN: 2444-3239 | Depósito Legal: M-19965-2015

Recibido el 27_04_2019 | Aceptado el 13_06_2019 | Publicado el 01_07_2019

\title{
EL REPORTAJE DE HISTORIAS DE VIDA COMO PUNTO DE PARTIDA DE LA RADIO DRAMATIZADA Y EL 'PODCAST' DE NO FICCIÓN EN EL ECOSISTEMA DIGITAL. ESTUDIO DE CASO: 'SIN MI IDENTIDAD' (CADENA COPE), 'LO CONOCÍ EN UN CORPUS' (PODIUM PODCAST) Y 'LAS TRES MUERTES DE MI PADRE' (CUONDA)
}

LIFE STORIES REPORTS AS A STARTING POINT FOR DRAMATIZED RADIO AND NON-FICTION 'PODCAST' IN DIGITAL ECOSYSTEM. CASE STUDY: 'SIN MI IDENTIDAD' (CADENA COPE), 'LO CONOCÍ EN UN CORPUS' (PODIUM PODCAST) AND ‘LAS TRES MUERTES DE MI PADRE’ (CUONDA)

\section{Laura Martínez-Otón}

lau.martinez.ce@ceindo.ceu.es iD https://orcid.org/0000-0002-2535-8282

Cristina Rodríguez-Luque

cristina.rodriguezluque@ceu.es iD https://orcid.org/0000-0002-3719-772X

Mario Alcudia-Borreguero

malcudia@ceu.es iD https://orcid.org/0000-0003-4707-0551

Universidad CEU San Pablo, de Madrid

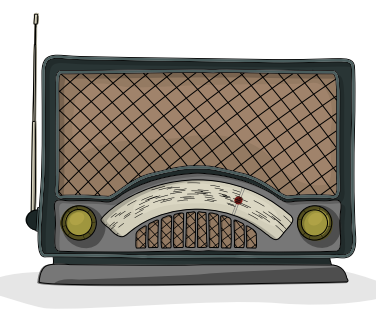

(c) (7) Para citar este trabajo: Martínez-Otón, L.; Rodríguez-Luque, C. y Alcudia-Borreguero, dramatizada y el podcast de no ficción en el ecosistema digital... index.comunicación, 9(2), 135-162. 
Resumen: En el ecosistema digital actual el sonido está alcanzando protagonismo a través de nuevos formatos como el podcasting, nacidos en la era de la movilidad. Formatos que pueden compartir elementos, características, dinámicas de trabajo y consumo con otros formatos tradicionalmente radiofónicos, como el reportaje, el docudrama o la radionovela. En este artículo se pretende analizar si la fuerza del human reach storytelling es un punto de partida común en los reportajes analógicos y en los podcasts de ficción y no ficción, tanto en plataformas de audio como en la radio convencional. Para ello, se plantea el estudio de caso de tres podcasts: 'Sin mi identidad' (2018, Cadena COPE), 'Lo conocí en un Corpus' (2017, Podium Podcast) y 'Las tres muertes de mi padre' (2017, Cuonda). La metodología utilizada es cualitativa descriptiva e incluye entrevistas semiestructuradas con sujetos clave en el proceso de los tres espacios objeto de estudio. En los casos analizados se puede afirmar que, si bien el reportaje y el podcast de ficción y no ficción son productos sonoros diferentes, comparten similitudes de producción, documentación y grabación. Asimismo, todos tienen como punto de partida común una historia real, incluso cuando el podcast es de ficción. Palabras clave: docudrama; podcast; radio; radio digital; radio dramatizada; reportaje radiofónico.

Abstract: In current digital ecosystem, sound is gaining prominence through new formats such as podcasting, born in the era of mobility. Formats that can share elements, characteristics, dynamics of work and consumption with other traditional radio formats, such as reports, docudramas or the radio soap opera. This article aims to analyze whether the strength of human reach storytelling is a common starting point in analogic reports and in fictional and non-fiction podcasts, both on audio platforms and on conventional radio. For this, three podcast are proposed as case study: 'Sin mi identidad' (2018, COPE network), 'Lo conocí en un Corpus' (2017, Podium Podcast) and 'Las tres muertes de mi padre' (2017, Cuonda). The methodology is classified as descriptive and qualitative and includes semi-structured interviews with key subjects in the process of the three spaces considered as objects of study. In the analyzed cases it can be stated that, although reports and fiction and nonfiction podcasts are different products, they share similarities of production, documentation and recording. Also, all have as starting point a real story, even when podcasts are fiction. Key words: Docudrama; Podcast; Radio; Digital Radio; Radio Drama; Radio Reports. 


\section{Introducción: de la radio analógica a la radio digital}

La radio demuestra continuamente que tiene la capacidad de conversión avalada por ser uno de los medios de comunicación con una mayor fidelización de audiencias. La búsqueda de nuevos formatos en el panorama abierto de la digitalización la ha convertido en un medio con gran resiliencia en los últimos cuarenta años. Mientras la prensa escrita y la televisión han ido perdiendo audiencias por el consumo digital o bajo demanda, la radio en España ha mantenido —e incluso aumentado, en determinados momentos - la confianza de sus oyentes (AIMC, 2019). En 1988 las audiencias en radio eran del 51,4 por ciento y en 2018 del 57,4 por ciento. Entre los años 2012 y 2016 se situaban por encima del 60 por ciento.

Este escenario de credibilidad (EBU, 2019) ${ }^{1}$ se ha conseguido no sólo por la búsqueda de un sonido de referencia basado en la calidad tecnológica, sino porque el sonido, la base de la razón de ser de la radio analógica, permite recibir la información con apenas esfuerzo para hacerse comprender (Santos Díez, 2003). Desde los comienzos, hasta la era digital en la que nos encontramos, la radio ha trabajado e innovado ya no sólo para mejorar coberturas o perfeccionar la calidad de su señal, sino para ofrecer una variedad de contenidos (Martínez-Costa, 2017).

En el ecosistema online actual, las empresas periodísticas se ven abocadas a intentar desarrollarse; a estar, porque, a pesar del déficit que puede suponer, lo contrario implica desaparecer (Campos Freire, 2011). Los programadores innovan para captar la atención de la audiencia expuesta a más información y entretenimiento que nunca en la era de la multiplataforma, a la que la radio también se suma.

La multiplataforma es la muestra patente de que la convergencia de medios ya no es ni una hipótesis, ni una opción, sino una 'necesidad' y 'exigencia', dotada de gran trascendencia que influye «de una manera decisiva en numerosas fases de la audiencia potencial mediante la programación simultánea» (Alcudia Borreguero; Barceló Ugarte y Legorburu Hortelano, 2012: 12). Algo que, además, construye imagen de marca «mediante acciones cruzadas, el incremento de ingresos por comercialización publicitaria (...) y la optimización de la gestión de los recursos, particularmente, de los económicos»».

1 La Unión Europea de Radiodifusión confirma a través de encuestas entre la población europea que la radio tiene la confianza del 85 por ciento de los europeos; mientras que las redes sociales son en las que menos se confía. 
Así, el medio ha ido incorporando formatos y adaptándolos a la nueva sociedad de la información. Según demuestra una investigación realizada entre 2014 y 2017 en la Cadena COPE, se recupera el formato del reportaje adaptado a los tiempos, en los programas informativos La Linterna (1987) y Mediodía COPE (2012), ajustándose a los parámetros de la radio de ese momento que busca seguir aumentando audiencias en la antena analógica e introducirse de pleno derecho en el ecosistema online (Martínez-Otón, 2019). De forma paralela, en esta época, comienza el desarrollo del fenómeno del podcasting, fruto de un nuevo consumo de sonido muy al hilo de la movilidad, donde el smartphone ha desbancado al receptor clásico y ha dado lugar a la radio de la pos-escucha (Sánchez Serrano, 2017).

Esta radio es sincrónica y asincrónica a la vez: ofrece últimas horas, pero también una programación troceada, recuperable, un entretenimiento para consumir bajo demanda del oyente prosumidor. De hecho, «el podcasting ha representado la primera innovación real, en lo que se refiere a la transformación de la radio en su relación con Internet, el móvil o las redes sociales» (Ortiz-Sobrino, 2016: 2).

Cuando Ben Hammersley acuñó ese término en el diario británico The Guardian (2004) planteaba una perspectiva de aficionados en la elaboración y difusión de mensajes radiofónicos hoy superada. El podcasting resulta un elemento imprescindible en la radio actual en nuestro país a juzgar por los 24 millones de descargas de los programas alojados en la plataforma Podium Podcast solo dos años después de su lanzamiento —-2016 — o los datos referentes a los podcasts más descargados que evidencian la importancia de un formato crucial en el ecosistema radiofónico contemporáneo (Pérez-Alaejos, Pedrero-Esteban, y Leoz-Aizpuru, 2018).

\section{1 'Podcasting' de ficción como heredero del docudrama}

El podcast viene a recuperar la ficción en la radio, el teatro radiado, las novelas de sonido, etc. que quedaron desplazadas en el momento en el que la imagen tomó el relevo del pódium de la comunicación (Rodríguez Pallarés, 2017). Esa radio mantiene su esencia acrecentada por las posibilidades de la tecnología, que aumenta la experiencia sonora de manera más envolvente. Como dice la BBC en su decálogo 
(2018): «podcasts are a visually powerful form of audio; they can be cinema for the ears»».2

Así, el podcast comparte con esas ficciones «la capacidad de engagement con narrativas más sofisticadas que la del radioteatro de los años treinta, porque la tecnología lo permite. El podcast es un híbrido muy interesante del que estamos conociendo sólo los primeros años, aún queda mucho por descubrir» (Espinosa de los Monteros, 2019). Quizás por eso, en Podium, lo que más se cuida en los podcasts es el guion. No se trata del sonido para la radio convencional. Porque el podcast de ficción es un contenido propio, es una narrativa diferente:

\begin{abstract}
Es muy difícil que contemos algo que no han contado ni la radio, ni la prensa, pero la forma sí podemos cambiarla porque no estamos constreñidos por unas señales horarias. Y luego la edición y posproducción. Intentamos siempre, y lo hemos ido consiguiendo, que una de las características de Podium, te gusten más o menos sus podcasts, es que sean de calidad. Es lo que nos puede diferenciar de podcasts independientes que tienen mucho éxito (Espinosa de los Monteros, 2019).
\end{abstract}

Los podcasts de ficción por los que apuesta Podium llevan detrás un plantel de conocidos actores - cuadro de actores - : Adriana Ugarte, Carlos Bardem, Jorge Perugorría, Terele Pávez y Nancho Novo, entre otros. Fichajes de voces que se consideran fundamentales para crear engagement y así poder crecer (Espinosa de los Monteros, 2019).

Estas características del podcast de ficción son parte del legado de la radionovela, del radioteatro, del radiodrama y de la radio de ficción interpretada. El podcasting de ficción es valedor de las características de la radionovela seriada que Rodero (2004) desgrana: el atractivo de una buena historia, ningún medio como la radio para la imaginación, identificación de los oyentes, complejidad en la elaboración e identidad propia, distribución en capítulos. Por su parte, Guarinos (1999: 51) asegura que la serialidad es la esencia de la radionovela, que condiciona la narración en cada episodio donde se dilata el conflicto que a veces se deja sin terminar, «o bien se resuelven, pero en capítulos siguientes se hace referencia a ellos contando con la competencia del receptor oyente a la hora de entender lo que allí se presupone».

2 «Los podcasts son una forma potente de audio, pueden ser cine para los oídos» (traducción de los autores). 
El docudrama es otro de los formatos en los géneros expresivos más propio de la era posmoderna (Idrovo-Carlier, 2001). Mezcla el drama con el documental para cohesionar de manera armónica un producto radiofónico. Tom W. Hoffer y Richard Alan Nelson (1978: 21) entienden este género como una combinación entre aspectos reales e imaginarios:

An unique blend of fact and fiction which dramatizes events and historic personages from our recent memory (...) The accuracy and comprehensiveness of such a recreation... can vary widely and is conditionated not only by intent but also by factors such as Budget and productions time. ${ }^{3}$

Raventós, Torregrosa y Cuevas (2012: 117-132) explican en 'El docudrama contemporáneo: rasgos configuradores’ esta «situación fronteriza entre la ficción y la no-ficción», es decir, la dramatización y los hechos reales en los que se basa el docudrama. Además, analizan el origen de la unión de estos dos términos que no es otro que «las variadas combinaciones terminológicas entre los conceptos de fact, fiction, drama, documentary, information». Por tanto, el docudrama es una mezcla de hechos, información y ficción contados con un estilo a medio camino entre el documental y la dramatización. Es Paget (1998) quien apunta los riesgos que supone mezclar ficción y realidad ya que puede verse como un ejercicio de falsificación, y existe una preocupación por la licencia dramática. No obstante, los productores, guionistas y expertos en docudrama huyen de las críticas por esta simbiosis entre realidad y ficción. Como tal, exige una actitud documental apoyada en el trabajo de documentación previo y reflejada en el modo de enfocar la historia (Raventós, Torregrosa y Cuevas, 2012).

Como recuerda Lipkin (2002), también se puede recurrir a la historia de la vida de una persona como tema del docudrama que va más allá de la narración de esa historia. Se abre la puerta a la exploración de la condición humana, su visión del mundo, sus aspiraciones o sus sentimientos a través de su manera de obrar ante las situaciones y acontecimientos reflejados en el dramático (Idrovo-Carlier, 2001).

3 Una mezcla única de realidad y ficción que dramatiza los acontecimientos y personajes históricos de nuestra memoria reciente (...). La precisión y la exhaustividad de tal recreación puede variar ampliamente y está condicionada no sólo por la intención, sino también por factores como el presupuesto y el tiempo de producción (traducción de los autores). 
En este formato, el oyente no sólo recibe una información que desconoce, sino que además puede verse reflejado o, por el contrario, rechazar la actitud de los personajes: «Docudrama's duty is to expose an audience to a subject it is interested in but knows nothing about it» ${ }^{4}$ (Rosenthal, 1999: 6). Idrovo-Carlier (2001: 52) sostiene que el éxito actual de este género reside en su capacidad de aunar «acontecimientos y sentido, lo simbólico, lo imaginativo, se muestra como forma idónea para hablar con verdad de los asuntos que realmente importan a la persona humana»».

Raventós, Torregrosa y Cuevas (2012: 124), apoyados en Paget y Lipkin, mantienen que el docudrama «obtiene mayores repercusiones sociales, morales y éticas», gracias a una mezcla de elementos que parten de «las raíces indexicales del drama documentary británico, la codificación melodramática del documentary drama americano». Todos estos son rasgos que se unen a otra característica destacada por Muñoz (2014: 6) que es que «el dramatizado tiene inmediatez», aunque ésta no está relacionada con «la actualidad del tema que se trate, sino que el modo de enfocarse responde al tiempo de permanencia o no de la situación en el contexto social».

\subsection{La fuerza de las historias de vida: cuando el reportaje y el 'podcast' comparten el punto de partida}

La exitosa fórmula del podcast de no ficción es representada en la máxima expresión por el título americano Serial ${ }^{5}$ (2014, serialpodcast.org). En años posteriores —2017 y 2018 - evoluciona hacia nuevos productos de podcasting periodísticos como Daily ${ }^{6}$ o Newsy, acuñando una nueva denominación para los podcasts de este tipo: narrative news. La noticia en este caso es el embrión del podcast abierto a la creatividad del formato. Mantiene en común con el reportaje que la noticia es el lugar de arranque del formato (Ulibarri, 1994). La noticia es el origen de cualquier información ampliada. Si no hay noticia, no hay reportaje. Como explica Martín

\footnotetext{
${ }^{4}$ La tarea del docudrama es exponer a la audiencia a un tema en el que está interesada pero no sabe nada sobre él (traducción de los autores).

${ }^{5}$ Se considera punto de inflexión del formato tras acumular en muy poco tiempo audiencias millonarias tras tres temporadas de emisión/distribución. Sólo en las siete primeras semanas consiguió diez millones de descargas. La historia está basada en una investigación periodística sobre un crimen real.

${ }^{6}$ El podcast diario de The New York Times lanzado en enero de 2017, lleva por título Daily.
} 
Vivaldi (1992), la noticia dotada de gran repercusión humana da cuenta, de un modo preciso pero completo, de un hecho actual o actualizado digno de ser conocido y divulgado.

Pero, por otro lado, el podcast y el reportaje se mantienen muy al hilo de la historia, porque es más fácil ser fieles a aquello que interiorizamos de forma sentimental; es el sistema límbico al lugar donde llega la radio y, aunque lo audiovisual impacta más, el sonido, despojado de todo, nos hace sentir; frente a eso no hay nada más importante. El hombre genera interés en el hombre y el reportaje ha de tener interés humano (Cebrián Herreros, 1992). Lo que nos lleva a reconocer que «el interés humano se halla en todos los detalles excepcionales de una persona vulgar $\mathrm{y}$ en todos los detalles vulgares de una persona excepcional. En lo que del hombre interesa al hombre» (Pérez Calderón, 1970: 38).

La radio busca nuevos formatos en el momento de la eclosión del podcasting, y los encuentra en el reportaje. En la investigación realizada sobre este formato en la radio analógica y la radio online (Martínez-Otón, 2019), se ha concluido que a los programadores de estos dos principales programas informativos de la Cadena COPE, Mediodía COPE y La Linterna les interesa programar en antena, entre 2014 y 2017 , las historias de vida (48,06 por ciento), frente a los reportajes puramente informativos (36,43 por ciento). Estos dos tipos de reportajes son los elegidos por el programador que además emite, en menor medida, los reportajes de declaraciones o de opinión, o los combinados que mezclan las historias de vida con la información o el análisis. Por otro lado, los temas de mayor interés son los sociales en un 69,7 por ciento. El análisis de los datos — 129 piezas analizadas en 1.200 horas de radioconfirma que el reportaje informativo es un formato integrador de otros como la entrevista, que aparece en el 88,37 por ciento de los elementos analizados.

Asimismo, en el reportaje human reach storytelling el periodista prefiere combinar todos los elementos sonoros basados en una buena postproducción que invita a emitirse en diferido. De hecho, mayoritariamente y según este estudio, se opta por la emisión en diferido. Esto permite cuidar el montaje y desarrollar el guion de manera más precisa y efectista para una experiencia sonora completa. 
Gráfico 1: el reportaje en COPE, 2014-2017, La Linterna y Mediodía.

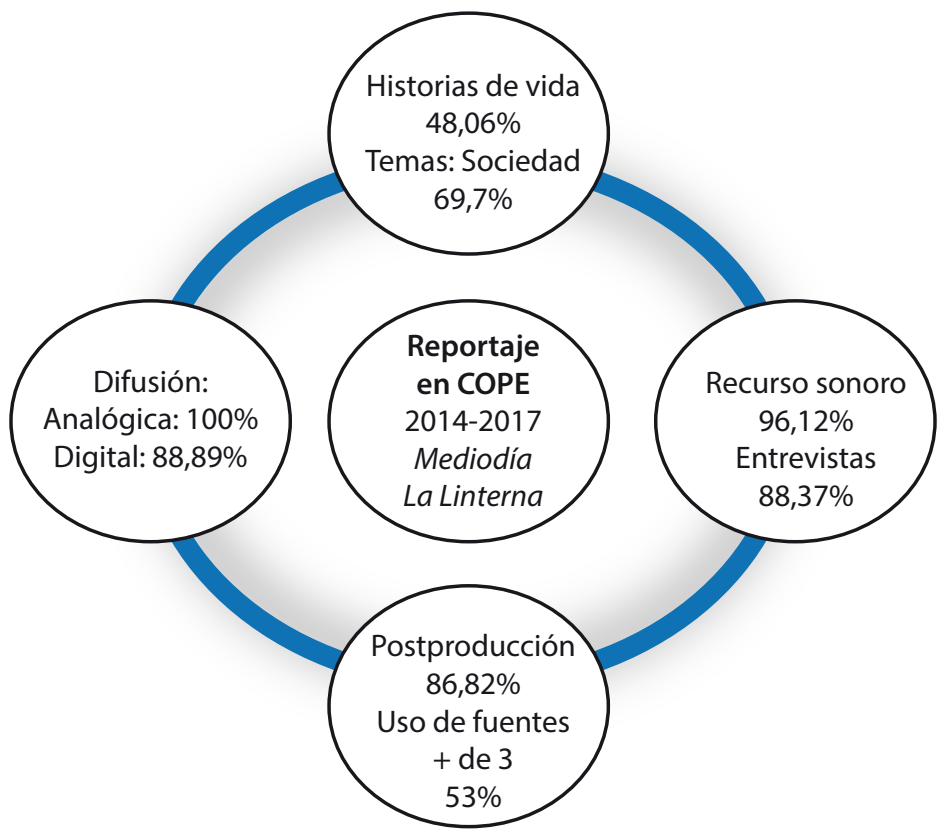

Fuente: elaboración propia.

En el estudio al que hacemos referencia se ha percibido que mientras que la mayoría de los reportajes puramente informativos emitidos en los programas de información estudiados - Mediodía COPE y La Linterna - no encuentran siempre su hueco en la web en los años del estudio -2014/2017—, sí se realiza, sin embargo, un producto multimedia cuando se trata de reportajes de historias, lo que se conoce como human reach storytelling. Otras variables a tener en cuenta son las que hacen referencia a los lenguajes y narrativas hipermedia y analizan la hipertextualidad. Ampliamente utiliza los elementos que componen el lenguaje audiovisual: texto web, fotos, vídeo y audio.

Todos estos datos, que marcan la taxonomía concreta de un tipo de reportaje, se intuyen en los podcasts de ficción y los narrative news o informativos. Se perciben como una historia con grandes testimonios que se apoyan en las entrevistas y los recursos sonoros, en la música y en los silencios. Son historias que interesan con un poso de realidad de la que arranca una distopía: 
Podcasts de ficción como ‘Guerra 3' habla de qué pasaría si estallara una guerra mundial, está ambientada en Corea del Norte, aparece Trump, aparece el Papa como gran líder que les pone a todos de acuerdo, aparece el problema de Cataluña. Es una ficción, pero hay una labor de documentación detrás muy grande para coger el pulso de lo que está sucediendo. 'El gran apagón' está basado en unos informes de la NASA que se pueden consultar en sus páginas y explican qué sucedería si hay un gran apagón solar, qué puede ocurrir (Espinosa de los Monteros, 2019).

Si bien, a la hora de trabajar, conviene recordar que la idea, el propósito, el enfoque, la investigación, la selección, el razonamiento, la confección o armado y la presentación son las fases básicas a las que se enfrenta la elaboración de un reportaje (Ulibarri, 1994). González Conde (2001) amplía estas fases y por delante de la documentación establece la necesidad de plasmar una línea argumental. Después de la investigación recomienda un guion de intenciones, escaleta o pauta; la localización de personas y lugares, creación de un guion previo; un plan de producción antes de la realización, para terminar con un guion definitivo antes del montaje.

\section{Metodología}

La metodología utilizada es cualitativa descriptiva. Por un lado, se ha utilizado la revisión bibliográfica, hemerográfica y documental de libros, artículos y recursos digitales relacionados con la ficción radiofónica —serial, radioteatro-, el docudrama, así como el reportaje de historias de vida. Aunque la metodología de este estudio no es el análisis de contenido, se han compartido resultados fruto de una investigación paralela sobre el reportaje en la radio informativa y que formarán parte de una tesis doctoral.

Por otro lado, se emplea un abordaje descriptivo de tres piezas de podcasting objeto de estudio que han sido elegidas porque representan tres casos del podcast de ficción y no ficción basados en hechos reales, en tres modelos empresariales distintos. Cadena COPE, como emisora de radio tradicional que apuesta por la ficción en su vertiente digital, en el caso de 'Sin mi identidad'; 'Lo conocí en un Corpus' como serial radiofónico promovido por la plataforma de Prisa, Podium Podcast; y 'Las tres muertes de mi padre', premio Ondas al Mejor Programa, Radio o Plataforma Radiofónica de Emisión online en 2018, que ha sido difundida en Cuonda, una comunidad independiente de podcasts. Además, se ha utilizado la entrevista semiestructurada (Vallés, 2014; Corbetta, 2007) para acudir a fuentes primarias. La población la constituían los responsables y equipo técnico de cada uno 
de los proyectos seleccionados. De esta población, la muestra se ha concentrado en cuatro entrevistas a miembros clave que han dirigido los tres títulos porque se consideraba que podían proporcionar la información necesaria para cubrir los objetivos planteados.

Para ello, se ha entrevistado a Noemí López Trujillo, autora de 'Lo conocí en un Corpus'; a Pablo Romero, autor y director de 'Las tres muertes de mi padre'; y a Andoni Orrantia, autor, productor y director de 'Sin mi identidad'. Para analizar las tendencias y futuro de este tipo de ficción se ha contado con María Jesús Espinosa de los Monteros, directora de Podium Podcast. Todas las entrevistas han sido transcritas y se ha llevado a cabo un proceso de revisión, estudio y selección de la información para responder a las propuestas iniciales.

\subsection{Hipótesis y objetivos}

Conforme al marco teórico expuesto y el análisis cualitativo descriptivo, como hipótesis general (H1) se plantea si el reportaje de historias de vida y la fuerza del human reach storytelling es un punto de partida común presente en los podcasts de ficción y no ficción 'Sin mi identidad' (Cadena COPE), 'Lo conocí en un Corpus' (Podium Podcast) y 'Las tres muertes de mi padre' (Cuonda) y si es posible inferir tendencias del panorama digital español actual en el que conviven la radio online y analógica.

En este sentido, como objetivo general se busca describir de forma detallada las diferencias y similitudes en los procesos de producción del reportaje de historias de vida y el podcast de ficción, así como el narrative news. De este objetivo general, se derivan los siguientes específicos:

- Exponer los argumentarios y datos técnicos de los tres títulos que constituyen nuestro caso de estudio: 'Sin mi identidad' (Cadena COPE), 'Lo conocí en un Corpus' (Podium Podcast) y 'Las tres muertes de mi padre' (Cuonda).

- Observar en qué medida tales podcasts se basan o no en historias reales detallando qué elementos tienen de hechos reales y qué de ficción; así como los procesos realizados por sus creadores en las labores de documentación y comprobar sus similitudes con las labores documentales realizadas por los periodistas en sus rutinas de trabajo. 
- Estudiar y analizar los procesos de producción sonora, guionización, grabación, edición y postproducción desarrollados en los podcasts objeto de estudio.

- Analizar, debatir y plantear con sus creadores la viabilidad empresarial de estos proyectos digitales y vislumbrar la proyección futura que prevén tener como propuesta innovadora de gestión de contenidos en el panorama radiofónico actual.

\section{Resultados: los casos de 'Sin mi identidad', 'Lo conocí en un Corpus' y 'Las tres muertes de mi padre'}

A pesar de los elementos que comparten, cada uno de los podcasts analizados parten de singulares diferencias. Los tres tienen como embrión un hecho que fue noticia, surgen de la actualidad. En los tres casos esa información fue recogida por los medios de comunicación y todos comparten el human reach storytelling como centro de sus narrativas. Se acercan a la historia de los protagonistas con una narración que aprovecha el lenguaje sonoro. Tratan temas de actualidad social como son la violencia machista, el terrorismo yihadista y los crímenes de ETA.

Las singularidades de cada uno hacen que en cada podcast la narración se resuelva de forma diferente. 'Sin mi identidad' es un podcast de ficción que complementa un proyecto transmedia junto a uno de no ficción, titulado 'El día que Abdul dijo adiós a Siria'. En el caso de 'Lo conocí en un Corpus', la autora lo sitúa cerca del documental sonoro. Mientras que para 'Las tres muertes de mi padre', según su creador, estaríamos ante una experiencia informativa fruto de una investigación jurídica. A continuación, se incluye una tabla con los principales datos recogidos y analizados de cada proyecto según la metodología descrita con anterioridad: 
Tabla 1: ficha resumen podcasts.

\begin{tabular}{|c|c|c|c|}
\hline $\begin{array}{c}\text { TíTULO } \\
\text { Y PLATAFORMA }\end{array}$ & $\begin{array}{l}\text { 'Las tres muertes } \\
\text { de mi padre' }\end{array}$ & $\underset{\text { PODCAST }}{\mathbb{D}}$ & 'Sin mi identidad' \\
\hline Guion & Pablo Romero & Noemí López Trujillo & Andoni Orrantia \\
\hline Producción y dirección & Pablo Romero & Podium Podcast & Andoni Orrantia \\
\hline $\begin{array}{l}\text { Número de episodios } \\
\text { y duración }\end{array}$ & $\begin{array}{l}5 \text { episodios } \\
\text { Entre } 18^{\prime} \text { y } 21^{\prime}\end{array}$ & $\begin{array}{l}4 \text { episodios } \\
\text { Entre } 18^{\prime} \text { y } 25^{\prime}\end{array}$ & $\begin{array}{l}8 \text { episodios } \\
\text { Entre } 14^{\prime} \text { y } 25^{\prime}\end{array}$ \\
\hline Denominación & $\begin{array}{l}\text { Podcast } \\
\text { Narrative news }\end{array}$ & $\begin{array}{l}\text { Podcast } \\
\text { Documental sonoro }\end{array}$ & Proyecto transmedia \\
\hline Motivación & Motivación personal & Motivación periodística & Motivación empresarial \\
\hline Tema & Investigación jurídica & Violencia machista & Terrorismo yihadista \\
\hline Tiempo de elaboración & Seis años de trabajo & Tres meses de trabajo & $\begin{array}{l}\text { Nueve meses de } \\
\text { trabajo }\end{array}$ \\
\hline Versiones de guiones & 7 versiones de guion & $\begin{array}{l}\text { Un pre-guion y } 4 \text { guiones, } \\
\text { uno por capítulo }\end{array}$ & 6 versiones de guion \\
\hline $\begin{array}{l}\text { Human reach } \\
\text { storytelling }\end{array}$ & $\begin{array}{l}\text { El atentado de ETA sin } \\
\text { resolver que asesinó a su } \\
\text { padre y } 6 \text { personas más en } \\
1993\end{array}$ & Asesinato de Ana Orantes & No \\
\hline Ficción sonora & No & No & $\begin{array}{l}\text { Intento de atentado } \\
\text { yihadista en el Teatro } \\
\text { Real de Madrid }\end{array}$ \\
\hline B.S.O & $\begin{array}{l}\text { Sí } \\
\text { David Barnet }\end{array}$ & No & $\begin{array}{l}\text { Sí } \\
\text { J.A. F. Machado y Lara } \\
\text { Morello }\end{array}$ \\
\hline Difusión analógica & No & $\begin{array}{l}\text { Cadena SER } 31 \text { diciembre } \\
2017\end{array}$ & $\begin{array}{l}\text { Cadena COPE } 11 \text { de } \\
\text { agosto de } 2018\end{array}$ \\
\hline Difusión digital & Web feed & Sin Web feed & Web Feed \\
\hline
\end{tabular}

Fuente: elaboración propia

'Sin mi identidad' es un podcast de ficción de la Cadena COPE que parte de la actualidad del yihadismo en un momento en que miles de refugiados sirios abandonan el país inmerso en una guerra, y cómo muchos de ellos son captados por 
el ISIS para combatir en toda Europa. Son ocho episodios con una duración de entre catorce y veinticinco minutos. El testimonio es para su director el 80 por ciento del podcast:

Si no hay testimonio, no hay podcast. Si Abul no hubiera abierto su corazón, sus sentimientos, sus vivencias, no hubiera habido podcast (...) Me llama la atención la historia del joven sirio Abdul, de Kobani, una ciudad kurda al norte de Siria. Con quince años es secuestrado por el Estado Islámico; después de sufrir tortura psicológica y física consigue huir, recorrer diez países y llegar a España. Es el primer menor sirio que adquiere el estatuto de refugiado. Es el momento en el que detecto la noticia. Empiezo a tirar de hilo y creo que la historia tiene la suficiente fuerza para realizar un doble viaje para un usuario con un reportaje y un podcast de ficción (Orrantia, 2019).

'Lo conocí en un Corpus' consta de cuatro episodios de entre dieciocho y veinticinco minutos de duración. López Trujillo es la autora, productora y hosts $^{7}$ del podcast. Se basa en la historia de Ana Orantes, una mujer asesinada por su marido días después de aparecer en televisión - Canal Sur - contando su vida como víctima durante cuarenta años de violencia machista. Los hechos ocurrieron en Cúllar Vega, Granada, el 17 de diciembre de 1997.

El podcast de Ana Orantes es, más que una reconstrucción de su vida, ver qué ha pasado, qué herida ha dejado no sólo a nivel institucional, sino en los familiares, un asesinato tan cruento. A Ana su marido la quemó viva. Es retomar una historia que ha sido contada pero siempre se ha contado lo mismo. Es recuperar un hecho de hace veinte años para mirarlo con la perspectiva temporal suficiente como para contarlo en un contexto adecuado, veinte años después qué ha implicado a nivel social e institucional (López Trujillo, 2019).

En este podcast aparecen ocho fuentes diferentes entrevistadas directamente por la autora, que pone en valor la fuerza de esos testimonios como el origen del éxito de la historia. También hace uso de fuentes documentales, cortes informativos de documentación de protagonistas políticos sobre el suceso. La autora es la voz narradora y en su elaboración - un proceso que ha durado tres meses, de octubre a diciembre de 2017 — han trabajado cuatro personas. El human reach storytelling es el centro del podcast de Noemí López Trujillo 'Lo conocí en un Corpus', un documental sonoro según la autora: «No me planteo hacer un trabajo como éste si no

${ }^{7}$ Término anglosajón para definir al narrador del podcast. La traducción exacta es anfitrión. 
hay una historia detrás. No quiero construir un personaje. Que exista una historia $a$ priori es básico, no tendría un hilo del que tirar». En los tres casos, es una fórmula repetida en el reportaje en radio: una historia que interesa y una manera innovadora de contarla.

'Las tres muertes de mi padre' gira en torno al asesinato sin resolver del teniente coronel del ejército del aire Juan Romero Álvarez, que viajaba junto a otros seis militares en la madrileña calle de Joaquín Costa en 1993. Consta de cinco capítulos de entre 18 y 21 minutos. En este caso, es el autor quien locuta. En su elaboración, han participado catorce profesionales durante más de seis años de trabajo.

Por pura casualidad consigo reabrir un caso que me toca personalmente: el asesinato de mi padre. Cuento la segunda muerte que no es otra que la prescripción del caso. Y, por último, la tercera muerte que esa es la clave. Yo no cuento el atentado o cómo me siento yo, cuento lo que me he encontrado, que es una apatía absoluta y un desinterés absoluto por todos los estamentos del Estado y de la sociedad civil. Lo nuevo, para mí, es el contraste del discurso público de empatía hacia las víctimas del terrorismo en general, y el desinterés absoluto por resolver lo que ha pasado (Romero, 2019).

En la elaboración de los podcasts analizados se percibe un proceso que se asemeja en determinados momentos, pero que adquiere peculiaridades estructurales diferentes.

La idea busca una función en cada caso. En 'Lo conocí en un Corpus', surge del interés periodístico de la autora por crear un trabajo sobre violencia machista y la necesidad de Podium Podcast de una serie sobre este tema. Es la plataforma de distribución la que plantea el trabajo. En el caso de 'Las tres muertes de mi padre' surge tras darse cuenta el autor que, después de cinco años y medio de investigación jurídica, y de trabajos periodísticos publicados en El Mundo y El Español, tiene más de noventa horas grabadas de entrevistas y sonidos a los que decide poner en orden para contarlo. Romero elige la plataforma Cuonda para producir y distribuir su investigación. 'Sin mi identidad' es un proyecto transmedia de COPE con la idea de contar la historia ficticia de Ahmed Rasic, un joven sirio. Con 28 años, su hermano gemelo es captado por el Estado Islámico para atentar contra el bicentenario del Teatro Real de Madrid. Él se convierte en confidente de la policía.

De las entrevistas se puede extraer que ninguno de los autores identifica sus trabajos como docudramas. No encuentran en la radionovela nada más que la estructura seriada por episodios. Eso sí, coinciden en que se usan los recursos 
sonoros del reportaje, pero se magnifican y potencian a la máxima expresión para conseguir un producto más rico en elementos. La historia de vida es el eje natural de los tres, en general del podcasting de ficción y del narrative news.

\subsection{Labor de documentación para reportaje y ficción}

El reportaje tradicional se sostiene gracias al peso de una importante documentación que permite dar al formato una profundidad y duración mayor que cualquier otra pieza informativa, algo que comparte con el podcast a juzgar por los datos observados. Se comprueba que la fase de documentación e investigación es una de las partes más importantes. López Trujillo (2019) cree que el trabajo comienza con la documentación. Para Romero (2019) es el 20 por ciento del trabajo y la razón de ser en 'Las tres muertes de mi padre'. La acumulación de entrevistas, al entonces Ministro del Interior, Rafael Vera, a etarras como López Rekalte, a comisarios de policía de la época, a confidentes... se complementan con entrevistas realizadas y buscadas para estar presentes en el podcast, entre otros a la esposa del asesinado, madre del autor.

Me doy cuenta cuando incorporo ya todos los indicios al sumario y consigo todo lo que quería, que este caso no iba a llegar a ningún lado porque existe un desinterés absoluto por resolver asesinatos para tapar las chapuzas del Estado. Entonces digo, ¿por qué no lo voy a contar? Ahora lo voy a contar no porque tengo que contarlo, sino porque quiero contarlo (Romero, 2019).

De la misma manera, la historia real de Abdul Haj Taher sirve para conceptualizar el punto de partida de 'Sin mi identidad'. Ese proceso implica «partir de dibujar algo que luego quieres plasmar en sonido, y luego en guion, al margen de las narrativas que uses» (Orrantia, 2019). Para poder recrear escenarios de ficción reales se trabaja con la Dirección de Información de la Policía Nacional y así conocer «qué encuentra la policía cuando entra en un piso del que ha huido una célula yihadista; cómo se comportan los yihadistas en un interrogatorio policial». El objetivo es enriquecer el guion. Era necesario estar asesorado por traductores árabes para las partes del guion en ese idioma. En este caso Orrantia, asegura que el proyecto creció en paralelo con 'El día que Abul dijo adiós a Siria' y la entrevista de acercamiento, preparación y, finalmente, grabación con el joven sirio aportaron fuerza emocional y sentimental al podcast de ficción. 


\subsection{Proceso de guionización}

Con el objetivo de dar forma completa a la narrativa, se ha observado en los podcasts analizados que, lo más frecuente, es crear un proceso de guionización por fases, al igual que proponen los autores para el reportaje radiofónico. Según relata el autor:

El 70 por ciento es el guion, es lo más importante y en lo que más tiempo hay que invertir. Tienes la investigación hecha, dejas abierto que surgirán algunas cosas mientras escribes el guion. El guion además te marca tu necesidad. Te va a marcar además la forma en la que vas a contarlo y qué quieres contar de verdad. Muchas veces arrancas con una historia y lo que vas a contar es otra. No engancha si no hay un trabajo exhaustivo de guion (Romero, 2019).

Para López Trujillo (2019) el guion comienza en una primera versión o preguion, que le permite saber la estructura en cuatro capítulos y lo que quiere contar en cada uno de ellos:

En función de eso yo podía distribuir la información necesaria y sabía por dónde empezar. Tenía claro que el último capítulo iba a ser recopilatorio de estos veinte años pues no me parecía empezar a buscar las entrevistas de las políticas desde el principio, porque sabía que de ahí me iban a salir otras entrevistas como la hermana de Ana, Carmen, la consuegra, la mujer de juez de paz... Decidí lo que quería que fuese en cada capítulo, pero la realidad se impone y enriquece lo que has escrito en ese pre-guion.

En el caso de Romero (2019), de las siete versiones de guion se utiliza la sexta. Elegir la narrativa dentro del proceso de guionización es una de las fases de la elaboración. Considera éste un trabajo arduo: «El trabajar el guion me dio la piedra de toque para saber que lo que buscaba es una narración clásica de novela negra». 'Las tres muertes de mi padre' está creado bajo el estilo clásico de guion audiovisual, con una estructura claramente buscada: «Una trama principal y unas subtramas que van marcando un ritmo de unos diez minutos y te sirven para enganchar en un momento dado y resolver más adelante o resolver en ese momento».

La elección de la narrativa a López Trujillo (2019) le viene marcada por la idea. Su guion está profundamente influenciado por una pregunta: «¿Qué nos une a Ana Orantes y a mí?». 
Una diferencia generacional, por qué estoy recuperando su historia, porque no la viví en primera persona, era mi necesidad de hablarle a ella en segunda persona. Como si yo tuviese el permiso de contar su historia. Como si la estuviera diciendo: Ana por primera vez vamos a contar tu historia bien.

El proceso de guionización pasa, en el caso de Romero (2019), por escribir una trama lineal; después una trama clásica unitaria, el principio en el final, y al revés creando flashbacks. 'Las tres muertes de mi padre' tiene una estructura de uno, tres, dos, cuatro, cinco, algo que permite intercalar otros hechos y enlazar capítulos con las subtramas. Primero escribió la trama general, todo el relato, y luego lo dividió en nueve capítulos lineales:

Con una pared de seis metros me hacía un pentagrama; se suelen poner seis o siete líneas con unos hilos o unas lanas en las que vas colocando tarjetas con lo que crees que puede ser un golpe concreto para mantener la atención sin bombardear. Cuando decidí que tenía que haber tres grandes subtramas, que eran las tres muertes, ahí surgió el título, y ahí surgió la necesidad de que lo arrancase y terminase mi madre por ser la persona más afectada.

Esto demuestra la necesidad de mantener el guion abierto hasta casi el último momento porque puede enriquecer el relato con algo inesperado. El guion es susceptible de cambios en cualquier momento. Orrantia confirma que se realizan pequeñas modificaciones hasta en el mismo momento de la posproducción, algo en lo que coincide con López Trujillo (2019):

No contaba con algunas entrevistas, con testimonios que fueron apareciendo y que no estaban en el planteamiento del guion. Yo estaba abierta a introducir cosas que enriquecieran mi trabajo. Y la aparición de nuevos testimonios que pudieran enriquecer el podcast fue primordial, era lo único que yo admitía para desviarme del camino.

A Pablo Romero (2019) el proceso de guionización le lleva seis meses. Es en la quinta versión del guion donde encuentra las claves para darle la narrativa deseada. Entonces, decide que desaparezca la voz omnipresente del narrador, e incluso incorpora el recurso del humor. López Trujillo (2019) recuerda que incluye una de las entrevistas clave del podcast al guion, cuando el primer capítulo estaba cerrado. Se trata de la hermana de Ana Orantes, Carmen. Fue la hija, Raquel Orantes, la que le hizo una entrevista íntima a su tía para recuperar la memoria de su madre. 'Sin mi identidad' pasó por más de seis versiones de guion. 
La fuerza del guion para Orrantia (2019) está en «distribuir los elementos de toda la historia en puntos muy concretos para alimentar esas ganas de saber del oyente para que no se quede saciado hasta el final. Que el oyente sienta curiosidad por lo que está pasando».

\subsection{Producción y posproducción}

La producción y posproducción es la fase en la que la pieza sonora comienza a tomar forma. Cuando hablamos de montaje radiofónico no se trata solamente de la modulación variable de las fuentes sonoras con las que el reportero cuenta, sino que también hacemos referencia al proceso técnico de la producción sonora. Es la fase final para la radio analógica, pero en el caso de los podcasts precede a la etapa de la distribución, una de las claves para hacer llegar el producto. Yuxtaponer los sonidos, las fuentes que ubiquen en el tiempo y en el espacio como si se tratara de secuencias de imágenes sonoras, gracias a la superposición de voces, de música con voz, de voz con efectos sonoros. Todo ello actualmente, con las nuevas técnicas de digitalización, permite que los costes sean menores y la calidad del resultado potencialmente alta.

En el caso de 'Lo conocí en un Corpus', la autora no ha participado in situ en el montaje. Ha sido el propio técnico de sonido apoyado en un guion completo y detallado de López Trujillo (2019) quien ha dado forma al podcast. Pablo Romero (2019), sin embargo, ha estado trabajando en la producción, controlando el montaje y cada sonido. Insiste en que su podcast no tiene de ficción más que unos recursos sonoros de ambientación: «Podríamos decir que hay grandes manipulaciones para intentar no manipular nada». Por su parte, Orrantia (2019) cree que el autor y director deben estar muy conectados con el diseñador sonoro: «Tienen que tener el mismo podcast en la cabeza para trabajar en la misma dirección».

En el caso de los dos podcasts de no ficción, la producción empieza con los recursos sonoros. En 'Las tres muertes de mi padre' encontramos entrevistas en cafeterías donde se mantiene el sonido real obtenido con la grabadora. Rafael Vera fue entrevistado en la cafetería Starbucks de la calle Princesa, de Madrid, con una grabadora encima de la mesa. El sonido ambiente se mantiene. En el caso de la entrevista con el etarra Rekalde, en un bar de Loyola, el autor descubre que mientras se narra cómo ponían las bombas lapa, suena de fondo, en la radio, la banda sonora de la película Qué bello es vivir (1946, Frank Cappa). Explica que «el técnico lo quería limpiar y yo insistí en no tocarlo. Ni aposta. Era un sonido perfecto». La 
simbología de ese momento espontáneo se suple en otros recursos buscando la intencionalidad de la grabación: «Cuando entrevisto a uno de los personajes en su despacho de Vitoria, insisto en que sea en su despacho porque necesito que reverbere, necesito que se oiga como si estuviera en una caja de zapatos — búsqueda del efecto desde la realidad-. Eso tiene una intención» (Romero, 2019).

Aquí, apenas algunos recursos ambientales acompañan la narración, o algunos documentales como el sonido de unos niños jugando en el primer caso o el sonido del estallido de la bomba que recoge Antena 3 en su matinal mientras entrevista al entonces ministro Álvarez Cascos. En el caso de 'Lo conocí en un Corpus' incorpora algún efecto ficcionado, como la marcación de una llamada de teléfono, pero todos sus sonidos son reales: «Tengo más de una hora de sonido ambiente porque era consciente de que había que grabar con los cinco sentidos» (López Trujillo, 2019).

Andoni Orrantia (2019) insiste en que la producción en un podcast de ficción incluye la grabación y el diseño sonoro, pero comienza por la localización y el casting de actores. En este producto sonoro intervienen 40 actores, que grabaron «cuatro horas diarias, durante varios días de la semana, durante un mes». Considera como parte de la producción el desarrollo de la web que se hizo de manera paralela con ilustraciones siguiendo el guion, y la creación de una banda sonora original a cargo de Juan Antonio Fernández Machado y Lara Morello.

Una de las cosas que se han cuidado con especial atención en 'Las tres muertes de mi padre' es la música:

Desde el primer momento decido que tiene que haber una sintonía muy identificable de tres notas, al final adquirimos los derechos de una. (...) David Barnet captó en seguida lo que necesitábamos, que era un contrapunto a esa melodía tan repetitiva de tres notas. Con el proceso de investigación aparece una guitarra rápida y la parte más humana, una música más cálida. La música empuja a la intencionalidad (Romero, 2019).

'Lo conocí en un Corpus' usa la música de manera intencionada desde la elaboración del guion. Pero si hay algo que el podcast admite y que la radio apenas prodiga, son los silencios; medidos de una manera casi «obsesiva» para Romero (2019): «No funciona un silencio de un segundo y siete milésimas, el que funciona es el de uno con cinco, porque el otro viola el ritmo, la cadencia y hasta el color que le quieres dar». La fuerza de la producción en este caso permite conseguir una historia real dramática sin que exista nada recreado. López Trujillo (2019) busca los sonidos reales que necesita para que su guion tenga la fuerza deseada. 
En los dos podcasts de no ficción descubrimos que no se busca una voz profesional de comunicador. Cumplen con una tendencia no escrita del podcasting, voces amateurs que imprimen confianza y cercanía:

En Podium lo teníamos claro: quien investiga la historia, quien se mete, tiene que ser quien la narre. No tiene sentido que no fuera así; sería hurtarle algo muy importante de una narración. En el caso de Noemí es curioso porque nunca había hecho radio y costó al principio, pero la fuerza de la historia es escucharla a ella cuando va a Granada y visita el lugar donde fue asesinada Ana Orantes; en el caso de Pablo que, es la historia de su padre, ¿quién la va contar mejor? (Espinosa de los Monteros, 2019).

Pablo Romero tardó dos días en grabar la locución de su podcast. Cree que no hubiera funcionado, no hubiera sido creíble; tiene valor porque lo ha vivido. Es una premisa del guion. Sin embargo, la inexperiencia en locutar trajo un problema en la producción porque se notaba la mecánica de la lectura. Ante este inconveniente idearon un sistema de locución:

Modifiqué el guion para poner algunas frases en mayúsculas. Yo iba leyendo y veía la frase, entonces contaba no lo que ponía, sino lo que me acordaba sin problema porque lo había escrito siete veces (...) El guion era de apoyo como un chivato, necesitaba que se me trabase alguna frase, algún coloquialismo, eso era fundamental. No me iba a salir si lo leía (Romero, 2019).

El podcast de ficción 'Sin mi identidad' cuenta con un plantel de actores y locutores con experiencia radiofónica e interpretativa para afrontar esta parte de la producción como Adryen Mehdi, Carlos Olalla o Natalia Varela, entre otros.

\subsection{Las labores de difusión}

La radio analógica ha entendido que tiene que buscar su hueco de difusión online. Las principales emisoras han convertido sus páginas webs en plataformas de distribución de audio con todos los contenidos que se manejan en la emisión analogical, pero también con contenidos nativos desde su concepción hasta su emisión.

En la radio digital se sitúa 'Sin mi identidad'. Como proyecto transmedia, cuenta con una importante web con el contenido crossmedia para ser consumido por el oyente. Por un lado, 'Nunca sucedió' con los episodios del podcast de ficción, material audiovisual, fotos, vídeo del making of, los protagonistas y un blog con las 
novedades. Y por otro, 'Ocurrió', el podcast de storytelling 'El día que Abdul dijo adiós a Siria', con los audios y las fotografías que apuntalan el lenguaje hipermedia, junto a varios vídeos de la misma temática. 'Sin mi identidad' encontró también su hueco en la radio analógica, emitiéndose una adaptación el 11 de agosto de 2018 de ocho a diez de la noche en la Cadena COPE.

'Lo conocí en un Corpus' y 'Las tres muertes de mi padre' son difundidas por dos plataformas de podcasting. Además, en el caso de Podium, donde se aloja el trabajo de López Trujillo, ha encontrado continuidad en la radio analógica. Los capítulos fueron emitidos el 31 de diciembre de 2017 en la Cadena SER.

Para Cuonda, plataforma donde se distribuye 'Las tres muertes de mi padre' la web feed es muy importante. Romero (2019) cree que, en la distribución, cuenta la necesidad para conseguir un buen posicionamiento SEO, de generar texto relacionado con la historia. Es relevante en el lenguaje transmedia y crossmedia del producto ofrecer - como es el caso del de Romero - los guiones completos (sexta versión con erratas incluidas) en la web; acompañarlos de fotografias editadas cuidadosamente para que la presencia de su padre, ausente en el audio, estuviera completa en el lenguaje audiovisual que complementa al audio. Además, incorpora los trabajos periodísticos del autor realizados durante la investigación: un gran reportaje en El Mundo - en primera persona cuenta cómo reabre el proceso-y otra serie de ocho crónicas en El Español. El objetivo era recabar pistas procesales.

En el caso de López Trujillo (2019), reconoce que la falta de tiempo ha sido la causa principal para no contar con el apoyo de una web que complementara el hipermedia de su historia más allá del montaje creativo de imágenes que suele crear Podium para sus podcasts.

Orrantia (2019) explica cómo los recursos de una radio analógica al servicio del podcasting complementan el resultado. 'Sin mi identidad' fue sometido a un focus group con oyentes la semana antes del estreno: «Lo que hicimos fue reunir a varios jóvenes que nada tenían que ver con el proyecto, que lo escucharan, y testar a ver si fallaba algo, se echaba de menos algo, si se les hacía largo, y fue una experiencia muy buena. Afortunadamente les pareció todo bien»».

\subsection{El 'podcast' como alternativa empresarial a la radio analógica}

Para conocer el éxito de la difusión de un podcast se hace referencia a las descargas conseguidas. No hay unanimidad en las plataformas para medirlo, por lo que es necesario un software para cruzar datos y no se pueden, por lo tanto, comparar 
audiencias. 'Las tres muertes de mi padre' cuenta hasta la fecha de la investigación con 140.000 descargas por capítulo, según confirma su creador. En el caso de los datos de 'Sin mi identidad' y 'Lo conocí en un Corpus', los autores han rehusado hacer públicas las cifras, y ello ha impedido vislumbrar la viabilidad económica que se planteaba inicialmente como objetivo de esta investigación.

Lo que sí sabemos es que el consumo de podcast no sustituye todavía al consumo radiofónico, que cuenta con el respaldo de las audiencias. Para Orrantia (2019) todavía no es una alternativa:

Lo uno no excluye a lo otro. La radio lineal sigue muy viva en España, el consumo de radio ha subido. No es rentable, pero la radio debe estar ahí. Tienen que apostar por una doble razón. Porque esas narrativas dobles se pueden aplicar a la radio para modernizarlas. Y, en segundo lugar, porque cuando esto sea un mercado que empiece a dar dinero el medio ya está posicionado (...) En España es pronto, no está socializado y cuando lo está es cuando tiene éxito.

Sin embargo, el modelo empresarial de Podium Podcast, a juzgar por las cifras duplicadas en un año, funciona. Tres años después de su lanzamiento en 2016, han superado los 40 millones de descargas. ${ }^{8}$

Los autores comparten la idea de que el podcasting es un modelo de negocio porque tiene la ventaja de ser un mercado potencial global que requiere de una inversión mínima, y porque Internet llega a donde las ondas no lo hacen. Es un modelo que necesita una gran plataforma para llegar a un público en masa, pero de momento está segmentado; no se puede pensar en un modelo de negocio publicitario como el que conocemos. Romero (2019) cree que los movimientos en el mundo de la comunicación son tendentes a ser conservadores, porque la televisión replica el modelo de la radio, e Internet replica el modelo de la televisión, y sin embargo, a su juicio, estamos en el momento en el que el audio debería salir de ese círculo:

Se puede hacer las dos cosas. El sonido está funcionando por otro lado. La radio se ha ido de la sonoridad, pero es muy fácil recuperarla. No dejó de funcionar nunca (la sonoridad), lo que pasó es que dejó de ser negocio, que es muy distinto. Pero puedes hacerlo todo. Puedes tener una parte exquisita, en la que te metas hasta el hueso del oyente, que se escuche como toda la vida muy de cerca (Romero, 2019).

${ }^{8}$ Datos oficiales de Podium en abril de 2019 (Espinosa de los Monteros, 2019). 
En 'Las tres muertes de mi padre', detrás, hay cinco años de investigación, seis meses de guionización y tres de posproducción. 'Sin mi identidad' se resolvió en nueve meses de documentación, guionización, producción y diseño sonoro. 'Lo conocí en un Corpus' llevó tres meses de trabajo. Es muy difícil para una radio analógica soportar varios proyectos de esta envergadura a la vez en el tiempo con la inversión económica y humana que requiere. En cuanto a presupuestos, de los treinta mil euros invertidos en 'Las tres muertes de mi padre', a los algo más de trescientos de 'Lo conocí en un Corpus', denotan que la inversión irá siempre en función de las necesidades tanto de producción como técnicas.

A día de hoy, de los casos estudiados se puede inferir que el podcasting de ficción no es todavía un producto rentable que pueda ser alternativa a la radio analógica. Así lo entienden en Podium donde se apuesta por el branded podcast como una importante fuente de ingresos que permite desarrollar el formato por el apoyo publicitario: «Para nosotros es una nueva forma de crecer, nos hemos convertido, además de en plataforma de podcasts claramente diferenciados, en una productora de sonidos con y para terceros» (Espinosa de los Monteros, 2019).

\section{Discusión y conclusiones}

Conforme a los resultados obtenidos, se demuestra que en los podcasts de ficción y no ficción analizados el reportaje de historias de vida y la fuerza del human reach storytelling puede ser un punto de partida común en el panorama radiofónico actual en el que conviven la radio online y analógica. A pesar de que los tres espacios analizados contienen elementos diferenciadores, parten de un hecho noticioso recogido por los medios de comunicación, compartiendo el human reach storytelling como centro de sus narrativas y acercándose a la historia de los protagonistas con guiones basados en la fuerza del sonido. Ahora bien, no sería prudente generalizar puesto que la metodología aplicada no permite demostrarlo, sino solamente deducir la tendencia. Para incidir más en ello sería necesario estudiar todos los proyectos existentes en el ecosistema radiofónico actual, tanto analógico como digital. Algo que - entendemos - abre una futura e interesante línea de investigación.

Los datos obtenidos en las entrevistas denotan que, si bien el reportaje y el podcast de ficción y no ficción son productos sonoros diferentes, comparten similitudes en las primeras fases del proceso. La documentación se trabaja en ambos casos de manera periodística, con el acceso a las fuentes y su posterior tratamiento. En la producción, la grabación de testimonios, entrevistas y recursos sonoros permite 
aplicar métodos similares, y esta labor condiciona el enfoque de la historia. En el caso de los podcasts de human reach storytelling, el tratamiento de la historia que se sigue es el mismo que el del reportaje. Se desprende que tienen como punto de partida una historia basada en hechos reales; incluso cuando el podcast es de ficción, detrás está la fuerza de una noticia que lo hace creíble.

La experiencia del consumo de sonido con auriculares condiciona la narración, distancia los dos formatos a la hora de elaborar guiones, producir sonidos y postproducir el resultado. Las narrativas contemporáneas permiten conseguir un resultado inmersivo a través del $8 \mathrm{D}$ o del 3D. En el caso de la radio analógica, el reportaje se crea para un consumo convencional de formatos lineales aunque, como reconocen los propios autores, el formato es exportable a la radio tradicional que se moderniza reivindicando el poder del sonido en un momento en el que el smartphone y los auriculares determinan un consumo mayoritariamente unipersonal.

La ficción, en el caso de los dos podcasts de storytelling analizados, apenas se usa y sólo se incorpora con el objetivo de ubicar y entender la narración. Se huye de la dramatización ficcionada; y si hay drama, es por el propio cariz de la historia. Para un podcast como 'Sin mi identidad' todo es ficcionado gracias a una potente narrativa que busca en la realidad sonora la manera de hacerlo convincente y engancha al oyente con un buen guion, un buen diseño sonoro, acompañado de un llamativo e interesante arranque.

Se ha comprobado en estos tres casos que, independientemente del género del formato podcast, la historia es la que determina la fuerza del resultado, condiciona el guion, planifica los testimonios e incluso establece la narración para llegar al oyente, estipula la duración de los episodios y fija su difusión. Los podcasts estudiados son productos sonoros que comparten rutinas de producción con el reportaje clásico, el documental o la radionovela, $\mathrm{y}$ han logrado un resultado con gran potencial de futuro en el ecosistema digital.

Las fuentes consultadas coinciden en que actualmente no es un formato rentable como para convertirse en una alternativa a la radio analógica. Ésta deberá convivir y apostar programando podcasting, para que, cuando se socialice el consumo, esté posicionada sabiendo qué y cómo tiene que hacerlo. Debido a lo incipiente del proceso, los productores guardan con celo las audiencias y resultados, por lo que no ha sido posible ahondar con profundidad en la viabilidad de los proyectos.

La difusión forma el último eslabón del éxito de un podcast. Episodios que nunca exceden los 25 minutos y que llegan a decenas de miles de oyentes, pero lejos 
de las audiencias millonarias de los programas de las principales emisoras analógicas. El consumo de estos espacios ha de luchar contra lo que denominan el factor olvido del oyente, publicando a la vez todos los episodios para que el usuario los tenga disponibles; todo ello, apoyado en una web feed de calidad con una experiencia transmedia completa.

\section{Referencias}

Alcudia Borreguero, M.; Barceló Ugarte, T. y Legorburu Hortelano, J. M. (2012). Convergencia de medios: Nuevos desafios para una comunicación global. Madrid: CEU Ediciones.

AIMC (2019). Marco general de los medios en España. Recuperado desde: https://www.aimc.es/a1mc-c0nt3nt/uploads/2019/01/marco19.pdf

AIMC (2019b). Navegantes en la Red- Encuesta AIMC a usuarios de Internet. Recuperado desde: https:/www.aimc.es/otros-estudios-trabajos/navegantesla-red/

CAMPOS FreIRE, F. (2011). El nuevo escenario mediático. Sevilla, Zamora: Comunicación Social.

CEBriÁN HERREROS, M. (1992). Géneros informativos audiovisuales: Radio, televisión, periodismo, gráfico, cine, vídeo. Madrid: Editorial Ciencia.

CorbetTA, P. (2007). Metodología y técnicas de investigación social. Madrid: McGraw-Hill Interamericana.

EBU (2019). Discurso de Noel Curram el Día de la radio. Recuperado desde: https://www.ebu.ch/news/2019/noel-curran-radio-days-europe-speech

ESPINOSA DE LOS MONTEROS, M. J. (2019). Entrevista personal (10 de abril) sin publicar.

GUARINOS, V. (1999). Géneros ficcionales radiofónicos: Revisión de conceptos y propuestas de una nueva tipología. Sevilla: MAD.

HOFFER, T. W. y NELSON, R. A. (1978). Docudrama on American Television. Journal of the University Film and Video Association, 30(2), 21-27.

IDROVO-CARLIER, S. (2001). El secreto está en el relato: fortalezas y retos del docudrama en la era posmoderna. Communication \& Society, 14(2), 37-70.

LIPKIN, S. N. (2002). Real emotional logic: Film and television docudrama as persuasive practice. Southern Illinois: University Press.

LÓPEZ TRUJILLO, N. (2019). Entrevista personal (4 abril) sin publicar. 
MARTínEZ-COSTA, P. (2017). Seis razones para seguir creyendo en la radio. Recuperado desde: https://medium.com/@mpmarcosta/seis-razones-paraseguir-creyendo-en-la-radio-af3b349cfb72

MARTín VIVALDI, G. (1992). Curso de redacción: Teoría y práctica de la composición y del estilo: del pensamiento a la palabra. Madrid: Paraninfo.

MARTíNEZ OTÓN, L. (2019). El uso del reportaje como formato en el nuevo discurso radiofónico. De la radio analógica informativa a la radio online en la Cadena COPE. Los casos de Mediodía COPE y La Linterna (2014-2017). Tesis doctiral no publicada. Universidad CEU San Pablo.

MUÑOZ, B. E. F. (2014). La producción de dramatizados radiales: una visión desde la cultura del trabajo. Revista Latina de Comunicación, actas del VI Congreso Internacional Latina de Comunicación Social.

ORRANTIA, A. (2019). Entrevista personal (10 de abril) sin publicar.

PAGET, D. (1998). No other way to tell it: Dramadoc/docudrama on television.

Manchester: Manchester University Press.

PÉreZ-Alaejos; M.; PEDRERO-ESTEBAn, L. M. y LeOZ AizPURU, A. (2018). La oferta nativa de podcast en la radio comercial española: Contenidos, géneros y tendencias. Fonseca, Journal of Communication, 17, 91-106.

PÉREZ CALDERÓN, M. y FERNÁNDEZ Asís, V. (1970). La información audiovisual. Madrid: Escuela Oficial de Radiodifusión y Televisión.

Raventós Mercadé, C.; Torregrosa Puig, M. y Cuevas Álvarez, E. (2012). El docudrama contemporáneo: rasgos configuradores. Trípodos, $1(29), 117-132$.

RODERO ANTÓN, E. (2004). La caja de los sueños: Un recorrido por el serial radiofónico en España. Salamanca: Universidad Pontificia de Salamanca.

RODRÍGUEZ PALLARÉS, M. (2017). Reutilización de la ficción sonora en la Cadena SER. El caso de Podium Podcast. Área Abierta. Revista De Comunicación Audiovisual y Publicitaria, 17(1), 83-97.

ROMERO, P. (2019). Entrevista personal (2 de abril) sin publicar.

ROSENTHAL, A. (1999). Why docudrama?: fact-fiction on film and TV. Carbondale: SIU Press.

SAntos DíEz, M. T. (2003). Periodismo radiofónico. Bilbao: Universidad del País Vasco Servicio Editorial. 
SÁNCHEZ SERRANO, C. (2017) La radio en tiempos de la posescucha. Recuperado desde: https://medium.com/@Cheloradio/la-radio-en-tiemposde-posescucha-90c37344b2d4

VALLÉS, M. S. (2014). Entrevistas cualitativas (2ºd.). Madrid: CIS.

\section{6. 'Podcasts' analizados:}

LÓPEZ TRUJILlO, N. (directora) (2017). Lo conocí en un Corpus [Audio podcast]. Recuperado de: https://www.podiumpodcast.com/lo-conoci-en-un-corpus/ ORRANTIA, A. (director) (2018). Sin mi identidad. [Audio podcast]. Recuperado desde: http://sinmiidentidad.cope.es/

ROMERO, P. (director) (2017). Las tres muertes de mi padre [Audio podcast]. Recuperado desde: https://www.lastresmuertesdemipadre.com/

\footnotetext{
cc) (7) Para citar este trabajo: Martínez-Otón, L.; Rodríguez-Luque, C. y Alcudia-Borreguero, M. (2019). El reportaje de historias de vida como punto de partida de la radio dramatizada y el podcast de no ficción en el ecosistema digital... index.comunicación, 9(2), 135-162.
} 